\title{
EDITORIAL Trastornos adictivos: un desorden prevenible
}

\author{
Dr. José Luis Zamudio Jiménez \\ PROFESOR DE TIEMPO COMPLETO \\ Universidad Iberoamericana Ciudad de México
}

EDITOR INVITADO

Las adicciones se pueden definir como un desequilibrio biopsicosocial-espiritual, donde el adicto utiliza una sustancia externa para aliviar el desbalance que sufre a distintos niveles (Fundación Girasol, 2002).

Explicar y comprender la anterior definición sería una tarea demasiado extensa para el espacio que nos ocupa. Sin embargo, esta forma de ver los comportamientos adictivos apunta a la manera adecuada de su prevención y tratamiento.

Existen distintos modelos para atender y tratar las adicciones. El enfoque multidisciplinario, en el cual hay distintos profesionales de la salud involucrados, es una forma de tratamiento que tiene sus orígenes en Europa continental o mediterránea. En esa zona geográfica existen clínicas especializadas en toxicomanías, donde médicos, psicólogos y trabajadores sociales están disponibles para la población que presente un problema con el abuso de alguna sustancia.

Las ventajas de contar con un equipo multidisciplinario de tratamiento son varias. Suponiendo que los profesionales en cuestión son bien intencionados y se encuentran adecuadamente informados, las terapias ofrecidas estarán basadas en evidencia científica y tomarán en cuenta la experiencia clínica del equipo. Esto evitará el uso de tratamientos no probados o peligrosos. Aunque en México hay centros con este enfoque, sería recomendable que los resultados de éstos fueran evaluados científicamente, para así determinar qué está funcionando y saber qué es necesario mejorar en este tipo de intervenciones.

En el nivel de prevención, el modelo biopsicosocial aporta una visión que vale la pena explorar. Los factores biogenéticos, estudiados especialmente para los problemas relacionados con el alcohol, ofrecen información oportuna, la cual puede recomendar la abstinencia a ciertas poblaciones, o bien medicaciones precisas de acuerdo con el perfil genético.

En lo psicológico, la presencia de ciertas características como la baja tolerancia a la frustración, la búsqueda constante de novedades y riesgos - por mencionar sólo unas pocas- puede orientar al profesional a cargo para realizar recomendaciones específicas en cuanto a las sustancias.

En lo familiar, la falta de adultos capaces de limitar, de forma adecuada, el comportamiento de los adolescentes debe encender un foco rojo. Este factor puede incrementar el riesgo de abuso de varias sustancias psicotrópicas.

Finalmente, el grupo de pares durante la adolescencia puede funcionar como una vacuna o foco de infección en lo que se refiere a las adicciones.

Este número ofrece tres artículos relacionados con el tema que nos ocupa; serían necesarios muchos más para atender un problema que va adquiriendo dimensiones epidémicas en nuestro país. • 


\section{REFERENCIAS}

Fundación Girasol (2002). Metodología de la Fundación Girasol. Recuperado de: http: /www.girasolfundación.es

Sussman, S., Lisha, N., \& Grifiths, M. (2011). Prevalence of the Addictions: A Problem of the Majority or the Minority? Eval. Health. Prof. March, 34(1), 3-56.

IAPACM (2013). Uso de drogas legales e ilegales en estudiantes de la Ciudad de México. Ciudad de México:. Instituto para la Atención y Prevención de las Adicciones. 